\title{
Modification of heat-induced whey protein gels by basic amino acids
}

Article

Accepted Version

Creative Commons: Attribution-Noncommercial-No Derivative Works 4.0

Wang, Y., Zhao, J., Zhang, W., Liu, C., Jauregi, P. and Huang, M. (2020) Modification of heat-induced whey protein gels by basic amino acids. Food Hydrocolloids, 100. 105397. ISSN 0268-005X doi: https://doi.org/10.1016/j.foodhyd.2019.105397 Available at https://centaur.reading.ac.uk/86870/

It is advisable to refer to the publisher's version if you intend to cite from the work. See Guidance on citing.

To link to this article DOI: http://dx.doi.org/10.1016/j.foodhyd.2019.105397

Publisher: Elsevier

All outputs in CentAUR are protected by Intellectual Property Rights law, including copyright law. Copyright and IPR is retained by the creators or other copyright holders. Terms and conditions for use of this material are defined in the End User Agreement.

\section{www.reading.ac.uk/centaur}

\section{CentAUR}

Central Archive at the University of Reading

Reading's research outputs online 
1 Modification of heat-induced whey protein gels by basic amino acids

3 Yaosong Wang ${ }^{1}$, Jing $\mathrm{Zhao}^{2}$, Weiwei Zhang ${ }^{1}$, Changqi $\mathrm{Liu}^{3, *}$, Paula Jauregi ${ }^{4}$, Meigui Huang ${ }^{1}$

4

$5 \quad{ }^{1}$ Department of Food Science and Engineering, College of Light Industry and Food Engineering,

6 Nanjing Forestry University, Nanjing 210037, China; ${ }^{2}$ School of Kinesiology and Nutritional

7 Science, California State University, Los Angeles, CA, USA 90032; ${ }^{3}$ School of Exercise and

8 Nutritional Sciences, San Diego State University, San Diego, CA, USA 92182; ${ }^{4}$ Department of

9 Food and Nutritional Sciences, The University of Reading, Whiteknights, RG 6AP, UK

10

11 *Address correspondence to this author: School of Exercise and Nutritional Sciences, San Diego

12 State University, San Diego, CA 92182-7251; Telephone: (619) 594-7753; Email:

13 changqi.liu@sdsu.edu

14 


\section{ABSTRACT}

16 Various amino acids have been studied as gelation enhancers. This study investigated the

17 effect of histidine, lysine, and arginine on gelling properties of heat-induced whey protein isolate

18 (WPI) gels at different pHs. Basic amino acids modified WPI gels in a pH- and amino acid-

19 dependent manner. Hardness and gumminess of the WPI gel was improved by arginine at $\mathrm{pH}$

207.59 while springiness was enhanced by histidine at pHs 7.59 and 9.74 and by lysine at $\mathrm{pH} 7.59$

$21(P<0.05)$. At pH 2.0, WPI formed a weak gel. Lysine and arginine facilitated $\beta$-lactoglobulin

22 cross-linking at $\mathrm{pH} 2.0$ and reduced protein leach out from the gel $(\mathrm{P}<0.05)$. At $\mathrm{pH} 5.2$, WPI

23 formed a particulate gel with poor water holding capacity (WHC). Lysine improved WHC of the

24 WPI gel at $\mathrm{pH} 5.2$ by changing the structure of the gel network. At pHs away from 5.2, basic

25 amino acid treatments resulted in a more uniform and porous gel matrix and a greater WHC $(P<$

26 0.05). In conclusion, different basic amino acids may be applied as WPI gel enhancers depending

27 on the $\mathrm{pH}$ and desired attributes of the product.

28 Keywords: Whey protein; Basic amino acids; Isoelectric point; Gelling properties 


\section{Introduction}

Recently, the application of amino acids as gelation enhancers has attracted considerable

32 attention. Amino acids such as arginine, cysteine, histidine, lysine, proline, and $\gamma$-aminobutyric

33 acid (Cando, Herranz, Borderías, \& Moreno, 2016; Liu et al., 2015; Primacella, Fei, Acevedo, \&

34 Wang, 2018; Wang, Liu, Ma, \& Zhao, 2019; Wang, Zhao, Liu, \& Li, 2019; Zhang, Wu, Jamali,

35 Guo, \& Peng, 2017) have been reported to improve gelling properties of a myriad of food protein

36 gels. Among these novel additives, basic amino acids, particularly lysine and arginine, have been

37 studied extensively. Adding basic amino acids resulted in gels with improved water holding

38 capacity, viscoelasticity and texture profile, and sensory attributes (Cando et al., 2016; Fu,

39 Zheng, Lei, Xu, \& Zhou, 2017; Hayakawa et al., 2012; Lei, Fu, Xu, Zheng, \& Zhou, 2016; Lei,

40 Fu, Zheng, Xu, \& Zhou, 2017; Qin, Xu, Zhou, \& Wang, 2015; Zhang et al., 2017; Zhou, Li, \&

41 Tan, 2014; Zhou, Li, Tan, \& Sun, 2014; Zhu et al., 2018). The underlying mechanisms include

$42 \mathrm{pH}$ modulation, reduced water mobility, increased protein solubility, suppressed protein

43 aggregation, altered protein thermal stability, facilitated protein unfolding and exposure of buried

44 hydrophobic groups and sulfhydryls, and formation of a fine gel network (Cando et al., 2016;

45 Chen et al., 2016; Fu et al., 2017; Gao, Wang, Mu, Shi, \& Yuan, 2018; Guo, Peng, Zhang, Liu,

46 \& Cui, 2015; Hayakawa et al., 2012; Lei et al., 2016; Lei et al., 2017; Li et al., 2019; Li, Zheng,

47 Xu, Zhu, \& Zhou, 2018; Qin et al., 2015; Zhang et al., 2017; Zhou, Li, \& Tan, 2014; Zhou, Li,

48 Tan, \& Sun, 2014). In addition, basic amino acids can improve emulsion stability (Zhu, Li, Li,

49 Ning, \& Zhou, 2019; Zhu et al., 2018), inhibit lipid and protein oxidation (Xu, Zheng, Zhu, Li, \&

50 Zhou, 2018), and stabilize heme color (Zhou, Li, \& Tan, 2014; Zhou, Li, Tan, \& Sun, 2014;

51 Zhou, Ye, Nishiumi, Qin, \& Chen, 2014; Zhou, Ye, Wang, Qin, \& Li, 2015), and are particularly

52 useful in emulsified gel systems such as sausages. 
Although extensive evidence has demonstrated that basic amino acids are effective in

54 improving quality of muscle protein gels (Fu et al., 2017; Hayakawa et al., 2012; Lei et al., 2016;

55 Lei et al., 2017; Qin et al., 2015; Zhang et al., 2017), egg yolk gel (Primacella et al., 2018), and

56 complex gel systems such as sausages (Zhou, Li, \& Tan, 2014; Zhou, Li, Tan, \& Sun, 2014; Zhu

57 et al., 2018), surimi (Cando et al., 2016), and cheese (Felicio et al., 2016), to the best of our

58 knowledge, no study has investigated the effect of basic amino acids on gelling properties of

59 whey protein isolate (WPI) gels. WPI is a widely used gelling and thickening agent in a variety

60 of foods such as processed meat, bakery products, and dairy products (Havea, Watkinson, \&

61 Kuhn-Sherlock, 2009). WPI gels can also serve as a carrier of bioactive substances or flavors

62 (Gunasekaran, 2008; Weel, Boelrijk, Alting, van Mil, Burger, Gruppen, Voragen, \& Smit, 2002).

63 The goal of this study was to investigate how histidine, lysine, and arginine would influence the

64 gelation of WPI. We hypothesized that addition of basic amino acids would result in changes in

65 properties of WPI gels such as gel strength and water holding capacity. This could serve as an

66 alternative method to $\mathrm{pH}$-based manipulation of gel properties, which are particularly

67 advantageous for foods produced at a given $\mathrm{pH}$. Several studies attributed part of the gelation

68 promoting effects of the basic amino acids to their ability to increase the $\mathrm{pH}$ (Fu et al., 2017; Qin

69 et al., 2015; Zhou, Li, \& Tan, 2014; Zhou, Li, Tan, \& Sun, 2014). Since there are more effective

70 and economic ways to adjust $\mathrm{pH}$, we controlled the $\mathrm{pH}$ in the current investigation and examined

71 the effectiveness of other mechanisms. Moreover, it is evident that the electrostatic interactions

72 between the basic amino acids and the proteins play an important role in the gelling process

73 (Cando et al., 2016; Lei et al., 2016; Lei et al., 2017). To uncover how the charge state would

74 affect the efficacy of the basic amino acids and to test the versatility of the application at 
75 different $\mathrm{pHs}$, we performed the experiments at $\mathrm{pH} 2.0$ and at the isoelectric point ( $\mathrm{pI}$ ) of

76 histidine ( $\mathrm{pH}$ 7.59), lysine ( $\mathrm{pH}$ 9.74), arginine ( $\mathrm{pH} 10.76)$, and $\beta$-lactoglobulin ( $\mathrm{pH} 5.2)$.

\section{2. Materials and methods}

79 2.1. Materials

Whey protein (WPI-90) was obtained from Hilmar Ingredients (Hilmar, CA, USA).

81 Histidine, lysine, and arginine were purchased from Sangon Biotech (Shanghai) Co., Ltd.

82 (Shanghai, China). All other chemicals were purchased from Sigma Aldrich (St. Louis, MO,

83 USA) or Sinopharm Chemical Reagent Co., Ltd. (Shanghai, China) and were of analytical grade.

85 2.2. Preparation of WPI sols

WPI was dissolved in deionized water to a concentration of $12 \%$ (w/v). Histidine, lysine,

87 or arginine was added to the WPI sol to a concentration of $0.5 \%(\mathrm{w} / \mathrm{v})$. The $\mathrm{pH}$ of the WPI sols

88 in the absence and presence of the basic amino acids was adjusted to 2.0, 5.2, 7.59, 9.74, and

89 10.76. WPI sols were stored at $4{ }^{\circ} \mathrm{C}$ until further use.

90

91 2.3. Particle size and $\zeta$-potential

92 Particle size and $\zeta$-potential of the basic amino acids-conditioned WPI sols were

93 determined according to Cheng, Chen, \& Xiong (2010) with modifications. The sols were diluted

94 to $1 \%$ WPI $(\mathrm{w} / \mathrm{v})$ in deionized water prior to the analyses. The particle size and $\zeta$-potential of the

95 samples were measured using a BT-90 Nano Laser Particle Size Analyzer (Bettersize

96 Instruments Ltd., Dandong, Liaoning, China) and a NanoPlus-2 Zeta Potential Analyzer

97 (Particulate Systems, Norcross, GA, USA), respectively. 


\subsection{Preparation of WPI gels}

Twenty-five milliliters of WPI sols (12\% w/v) in the absence and presence of $0.5 \%(\mathrm{w} / \mathrm{v})$

101 basic amino acids were added to cylindrical containers with an internal diameter of $35 \mathrm{~mm}$ and a

102 height of $30 \mathrm{~mm}$ and were heated in a water bath at $90{ }^{\circ} \mathrm{C}$ for $30 \mathrm{~min}$. Samples were

103 subsequently cooled to room temperature $\left(\mathrm{RT}, 23^{\circ} \mathrm{C}\right)$ in an ice water bath followed by an

104 overnight incubation at $4{ }^{\circ} \mathrm{C}$.

105

106

\subsection{Color measurement}

Color of the WPI gels were measured using an SC-10 portable colorimeter (Shenzhen

108 Threenh Technology Co., Ltd., Shenzhen, Guangdong, China). L*, a*, and b* values of the 109 samples were determined using $4 \mathrm{~mm}$ aperture, 8/d geometry, and D65 illuminant.

111 2.6. Texture profile analysis

112 WPI gels were subjected to texture profile analysis using a TA.XT plus texture analyzer

113 (Stable Micro Systems Ltd., Godalming, United Kingdom) with a 5 kg load cell, 3.5-inch

114 diameter metal compression platen, $1 \mathrm{~mm} / \mathrm{s}$ pre-test speed, $2 \mathrm{~mm} / \mathrm{s}$ compression speed, $10 \mathrm{~mm}$

115 compression distance, and $5 \mathrm{~g}$ trigger force (Cheng et al., 2019). Hardness was defined as the

116 maximum force of the first compression. Resilience was defined as ratio of upstroke-to-

117 downstroke energy of the first compression. Springiness was defined as the ratio of the second

118 compression distance to the first compression distance. Cohesiveness was defined as ratio of the

119 second compression energy to the first compression energy. Gumminess was defined as hardness 
$120 \times$ cohesiveness. Chewiness was defined as hardness $\times$ cohesiveness $\times$ springiness (Bourne,

121 2002).

122

123 2.7. Water holding capacity (WHC)

124 WHC was measured by centrifuging $2 \mathrm{~g}$ of WPI gel samples in centrifuge tubes with a 125 small piece of filter paper at $3000 \times g$ for $20 \mathrm{~min}$. WHC was calculated according to Equation 126 (1).

$$
\mathrm{WHC}(\%)=\frac{\mathrm{W}_{2}}{\mathrm{~W}_{1}} \times 100 \%
$$

Where $\mathrm{W}_{1}$ is the initial weight of the gel and $\mathrm{W}_{2}$ is the gel weight after centrifugation

128 (Wu, Xiong, Chen, Tang, \& Zhou, 2009).

\subsection{Swelling ratio}

A cylindrical gel (diameter $\times$ height $=8 \mathrm{~mm} \times 10 \mathrm{~mm})$ was cored from the center of the

132 gel samples and heated at $50{ }^{\circ} \mathrm{C}$ in deionized water. The gel was blotted dry and weighed, and

133 the swelling ratio was calculated according to Equation (2).

$$
\text { Swelling ratio }(\%)=\frac{\mathrm{W}_{2}-\mathrm{W}_{1}}{\mathrm{~W}_{1}} \times 100 \%
$$

134 Where $\mathrm{W}_{1}$ is the initial weight of the gel and $\mathrm{W}_{2}$ is the weight of the swollen gel (Ozel,

135 Cikrikci, Aydin, \& Oztop, 2017).

\subsection{Protein leachability}

Two grams of WPI gel was immersed in $8 \mathrm{~mL}$ of $0.05 \mathrm{M}$ sodium phosphate buffer $(\mathrm{pH}$

$1397.0)$ at room temperature for $2 \mathrm{~h}$ with manual shaking every $30 \mathrm{~min}$. Subsequently, samples were centrifuged at $3000 \times g$, room temperature for $10 \mathrm{~min}$. Soluble protein concentration in the 
141 supernatant was determined by the Biuret method, and protein leachability was measured as the

142 percentage of protein that leached out of the gel (Wang, Xiong, Rentfrow, \& Newman, 2013).

143 The leached-out proteins were subjected to sodium dodecyl sulfate-polyacrylamide gel

144 electrophoresis (SDS-PAGE).

145

146 2.10. SDS-PAGE

147 The supernatant from the protein leachability test was mixed with sample buffer (10 mM

148 Tris- $\mathrm{HCl}, 10 \%$ v/v glycerol, $2 \%$ w/v SDS, $0.02 \%$ bromophenol blue, $\mathrm{pH}$ 8.0) with and without

$1495 \%(\mathrm{v} / \mathrm{v}) \beta$-mercaptoethanol $(\beta \mathrm{ME})$ at $1: 1$ ratio and boiled for $3 \mathrm{~min}$. For samples without $\beta \mathrm{ME}$,

$150 \quad 0.5 \mathrm{mM}$ N-ethylmaleimide (NEM) was added to prevent artificial disulfide bond formation.

151 Samples $(20 \mu \mathrm{L})$ were loaded along with molecular weight standards and electrophoresed on a

$1525 \%$ polyacrylamide stacking gel $(20 \mathrm{~mA} / \mathrm{gel})$ and a $12.5 \%$ polyacrylamide resolving gel (40

$153 \mathrm{~mA} / \mathrm{gel})$. The gels were stained using Coomassie Brilliant Blue R250 for $3 \mathrm{~h}$ and de-stained with

$1547.5 \%(\mathrm{v} / \mathrm{v})$ acetic acid and 10\% (v/v) methanol until the background was clear (Laemmli, 1970).

\subsection{Scanning electron microscopy}

A Quanta-200 scanning electron microscopy (FEI Company, Eindhoven, Netherlands)

158 was used to examine the microstructure of the WPI gels. A sharp razor was used to cut the WPI

159 gels. Cross-sections of the gels were mounted on a bronze stub and sputter-coated with gold prior

160 to microscopic observation (Wang et al., 2013).

161

162 2.12. Statistical analysis 
All experiments were replicated at least twice with triplicate measurements in each

164 replication. One-way ANOVA was used to compare means for difference with Statistix 9.0

165 (Analytical Software, Tallahassee, FL, USA). Fisher's least significant difference (LSD) test was 166 used as post-hoc test at $P \leq 0.05$.

168 3. Results and discussion

169 3.1. Particle size and $\zeta$-potential of WPI sols

170 The aggregation and gelation of the WPI are largely dependent on the $\mathrm{pH}$ and surface 171 charge of the proteins (Brodkorb, Croguennec, Bouhallab, \& Kehoe, 2016). To test whether the 172 addition of basic amino acids would influence these important properties, particle size and $\zeta$ 173 potential of the WPI sols were determined at different $\mathrm{pHs}$ in the absence and presence of basic 174 amino acids. WPI sols registered similar average particle size (397-427 nm) at pH 2.0, 7.59, 175 9.74, and 10.76 (Fig. 1A). At pH 5.2, WPI formed significantly $(P<0.05)$ larger particles $(1728$ $176 \pm 30 \mathrm{~nm})$. These results were in agreement with previously observations that heat-induced 177 aggregation of $\beta$-lactoglobulin at its $\mathrm{pI}$ led to large particle formation whilst smaller particles 178 were obtained at pHs far from the pI (Guo, Harris, Kaur, Pastrana, \& Jauregi, 2017). The lack of 179 net charge on the protein surface at the pI promoted protein aggregation while strong repulsive 180 interactions between charged protein molecules at $\mathrm{pHs}$ far from $\mathrm{pI}$ hindered aggregation. At all 181 the $\mathrm{pH}$ values tested, the addition of basic amino acids did not change the particle size of the 182 WPI to a great extent. As shown in Fig. 1B, the WPI sol exhibited a $\zeta$-potential of $-4.52 \pm 0.40$ $183 \mathrm{mV}$ at $\mathrm{pH}$ 5.2. The addition of basic amino acids changed the $\zeta$-potential to slightly positive $184(0.31-2.05 \mathrm{mV})$. At $\mathrm{pH} 2.0$, the WPI sol had a $\zeta$-potential of $8.73 \pm 0.98 \mathrm{mV}$ due to the 185 protonation of the carboxyl and amine groups. The $\zeta$-potential increased in the presence of lysine 
$186(11.55 \pm 0.52 \mathrm{mV})$ and arginine $(13.95 \pm 0.04 \mathrm{mV})$, while decreased slightly in the presence of 187 histidine $(5.50 \pm 0.11 \mathrm{mV})$. At $\mathrm{pH} 7.59$, the $\zeta$-potentials of the control $(-26.71 \pm 0.29 \mathrm{mV})$ and 188 histidine added sample $(-26.32 \pm 0.23 \mathrm{mV})$ were not significantly different $(P>0.05)$, while the 189 samples with the addition of lysine and arginine had lower $(P<0.05)$ negative $\zeta$-potentials $(-$ $19020.55 \mathrm{mV}$ to $-20.96 \mathrm{mV}$ ). Since lysine and arginine are strongly cationic at pHs $2.0-7.59$, these

191 results are expected. At pH 9.74 and 10.76, no difference in $\zeta$-potential (-30.09 $\mathrm{mV}$ to -31.84 $192 \mathrm{mV}$ ) was found between samples possibly due to extensive deprotonation of the WPI and amino 193 acids (Miyatake, Yoshizawa, Arakawa, \& Shiraki, 2016).

\subsection{Appearance and color of WPI gels}

Appearance and color are important quality indicators of gels. During gel preparation,

197 substantial color differences between treatments were noticed (Figure 2). The distinct differences

198 in the surface charge and particle size of WPI at pH 5.2 in comparison to the other $\mathrm{pH}$ values

199 were reflected on the appearance of the WPI gels. The WPI formed white, opaque gels at pH 5.2

200 and translucent gels at the other pHs regardless of the absence or presence of the basic amino

201 acids (Fig. 2). It has been well documented that WPI forms a coarse particulate gel when there is

202 limited electrostatic repulsion and a fine-stranded gel when the repulsive forces are dominant

203 (Langton \& Hermansson, 1992). The control WPI gel at pH 2.0 was not able to withhold its

204 shape. Although WPI is capable of forming fine-stranded gels at low pHs, such gels are weak

205 due to the lack of disulfide bond formation (Shinya Ikeda \& Morris, 2002). The addition of the

206 basic amino acids improved gel rigidity at $\mathrm{pH}$ 2.0. The basic amino acids also enhanced the

207 gelation of the WPI at pH 7.59 and 9.74 based on the appearances of the gels. It has been

208 reported that the addition of basic amino acids can expose buried hydrophobic groups and 
reactive sulfhydryl groups and contribute to an enhanced protein gelation (Guo et al., 2015; Lei

210 et al., 2016; Lei et al., 2017).

211 The color measurements of the gels corresponded well with the visual appearance (Table

212 1). The particulate gels at $\mathrm{pH} 5.2$ had considerably higher $\mathrm{L}^{*}$ values than gels at other $\mathrm{pHs}(P<$

213 0.05). With the exception of the particulate gels at $\mathrm{pH}$ 5.2, which reflected most of the colors, the

214 increase in $\mathrm{pH}$ and the addition of lysine and arginine resulted in significantly higher yellowness

215 values $(P<0.05)$. The yellow color was likely resulted from Maillard browning reaction between

216 the residual lactose $(0.2 \%)$ and proteins/amino acids, which was favored at high pHs and with

217 the addition of free amines.

219 3.3. Texture profile analysis

220 Except for the WPI gel containing 0.5\% arginine, the gel strength peaked at $\mathrm{pH} 5.2$,

221 decreased in the $\mathrm{pH}$ range of 5.2 to 9.74, and increased again when the $\mathrm{pH}$ reached 10.76 (Fig.

222 3). In the presence of $0.5 \%$ arginine, the highest gel hardness was achieved at $\mathrm{pH} 7.59$. Gel

223 resilience did not exhibit appreciable changes in acidic $\mathrm{pHs}$, but increased drastically when $\mathrm{pH}$

224 was raised to 7.59, and then leveled off at higher pHs. The control gel had a higher gel resilience

225 at $\mathrm{pH} 2.0$, while a lower gel resilience at $\mathrm{pHs}$ 7.50-10.76 in comparison to those containing basic

226 amino acids. The lowest gel springiness was observed at pH 5.2 for all samples. Treatment with

$227 \quad 0.5 \%$ histidine at pHs 7.59 and 9.74 resulted in the springiest WPI gels followed by the treatment

228 with $0.5 \%$ lysine at $\mathrm{pH} 7.59$. Gel cohesiveness increased in the $\mathrm{pH}$ range of 2.0 to 7.59 and

229 leveled off at higher pHs. The gels were the least cohesive in the presence of $0.5 \%$ lysine and

230 arginine at $\mathrm{pH}$ 2.0. The addition of basic amino acids exhibited a trend towards higher gel

231 cohesiveness at basic pHs. Gumminess of the gel displayed a similar pattern as gel hardness. 
232 WPI gel at $\mathrm{pH} 7.59$ in the presence of $0.5 \%$ arginine exhibited the highest gumminess.

233 Chewiness is mutually exclusive from gumminess and is not applicable to gels (Bourne, 2002).

234 Whey proteins agglomerate extensively at $\mathrm{pH} 5.2$ due to weak electrostatic repulsions

235 and form particulate gels that fracture at relatively large stress (Ikeda \& Foegeding, 1999; Shinya

236 Ikeda, Foegeding, \& Hagiwara, 1999; Stading \& Hermansson, 1991). However, such gels are

237 mainly composed of loosely-linked large, spherical particles with fewer junctions as compared to

238 the fine-stranded gels (Ikeda \& Morris, 2002; Langton \& Hermansson, 1992). During the texture

239 profile analysis, these brittle gels failed to withstand the second compression and resulted in the

240 poor resilience, springiness, and cohesiveness. Although $\beta$-lactoglobulins form fine-stranded gels

241 at both low and high $\mathrm{pHs}$, the microstructure and texture of the gels are different. At low pHs, $\beta$ -

242 lactoglobulin gels are composed of short, stiff strands and are fragile and brittle (Langton \&

243 Hermansson, 1992). The low thiolate/thiol ratio and less frequent thiol/disulfide interchange rate

244 at low pHs also contribute to the fragility of the gels (Monahan, German, \& Kinsella, 1995;

245 Zhou, Liu, \& Labuza, 2008). On the contrary, the high pH gels have extensive disulfide cross-

246 links and curled strands with long junction zones and a rubbery texture (Langton \& Hermansson,

247 1992).

248 The addition of basic amino acids modified the texture of the WPI gels. Several studies

249 have demonstrated that basic amino acids strongly bind to the charged residues of proteins

250 through electrostatic interactions, which alters the structure and thermal properties of the proteins

251 and in turn affect their gelling properties (Guo et al., 2015; Lei et al., 2016; Lei et al., 2017;

252 Zhou, Li, \& Tan, 2014). Gel hardness and gumminess increased significantly $(P<0.05)$ at $\mathrm{pH}$

2537.59 when $0.5 \%$ arginine was added. Arginine-induced increase in hardness/strength of chicken

254 salt-soluble protein gel (Qin et al., 2015), actomyosin gel (Lei et al., 2016), chicken sausage (Zhu 
255 et al., 2018), and pork sausage (Zhou, Li, Tan, \& Sun, 2014) have also been reported. Lei et al.

256 (2016) demonstrated that arginine increased the surface hydrophobicity and reactive sulfhydryl

257 groups of chicken actomyosin, both of which are critical for the gel network formation. The

258 addition of histidine ( $\mathrm{pHs} 7.59$ and 9.74) and lysine ( $\mathrm{pH} 7.59)$ significantly increased gel

259 springiness $(P<0.05)$. Lysine-induced increases in springiness of pork sausage (Zhou, Li, \&

260 Tan, 2014) and chicken sausage (Zhu et al., 2018) have been reported. Lysine enhanced the

261 thermal stability of the proteins and induced formation of a more compact, uniform, and elastic

262 gel matrix (Zhou, Li, \& Tan, 2014; Zhu et al., 2018). Gao et al. (2018) reported that histidine

263 suppressed fierce aggregation of carp myosins and induced the proteins to form finer aggregates

264 and a more ordered network. In addition, charge screening of the WPI by the positively charged

265 basic amino acids reduced electrostatic repulsion and promoted protein aggregation and gel

266 formation (Unterhaslberger, Schmitt, Sanchez, Appolonia-Nouzille, \& Raemy, 2006). This

267 explained why lysine and arginine were the most effective at $\mathrm{pH} 7.59$. As shown in Fig. 1, lysine

268 and arginine significantly $(P<0.05)$ reduced the negative $\zeta$-potential of the WPI at pH 7.59. The

269 charge screening effect diminished at higher pHs due to extensive deprotonation of the WPI and

270 amino acids (Miyatake, Yoshizawa, Arakawa, \& Shiraki, 2016).

272 3.4. WHC and swelling ratio

273 As expected, WPI gels had the lowest WHC at pH 5.2 (Fig. 4A). Particulate gels are

274 known to have poor WHC. As shown in Fig. 2, the WPI gels at pH 5.2 exhibited extensive

275 syneresis. The particulate gels have much larger pore sizes $(\mu \mathrm{m})$ than the fine-stranded gels $(\mathrm{nm})$

276 and thus have weaker capillary forces to entrap water (Stading, Langton, \& Hermansson, 1993).

277 The addition of basic amino acids increased the WHC at all pHs except for $\mathrm{pH}$ 5.2, at which only 
$2780.5 \%$ lysine resulted in a significantly higher WHC $(P<0.05)$. Histidine, lysine, and arginine

279 have been reported to improve WHC of chicken salt soluble protein gel (Qin et al., 2015),

280 chicken myosin gel (Fu et al., 2017), surimi gel (Cando et al., 2016), porcine myosin gel (Zhang

281 et al., 2017), and pork sausage (Zhou, Li, \& Tan, 2014; Zhou, Li, Tan, \& Sun, 2014). Some of

282 the studies attributed the enhanced WHC to basic amino acid-induced $\mathrm{pH}$ deviation away from $\mathrm{pI}$

283 (Fu et al., 2017; Qin et al., 2015; Zhou, Li, \& Tan, 2014; Zhou, Li, Tan, \& Sun, 2014). However,

284 since the $\mathrm{pH}$ of the samples were controlled in the current investigation, factors other than $\mathrm{pH}$

285 shifting must have also contributed to the increased WHC. Basic amino acid-induced increase in

286 protein solubility and hydration capacity ( $\mathrm{Li}$ et al., 2019; Li et al., 2018), suppression of protein

287 aggregation (Qin et al., 2015), reduction in water mobility (Fu et al., 2017; Zhang et al., 2017),

288 and formation of a fine gel structure (Fu et al., 2017; Qin et al., 2015) have been suggested as

289 possible mechanisms.

290 During the swelling ratio test, all the pH 2.0 WPI gels collapsed when heated in

291 deionized water. As shown in Fig. 4B, the swelling ratio of the WPI gels increased significantly

292 when the $\mathrm{pH}$ increased from 5.2 to $7.59(P<0.05)$. The swelling property of a gel is largely

293 dependent on its microstructure (Abaee, Mohammadian, \& Jafari, 2017). The particulate gels are

294 less flexible than the fine-stranded gels and only swell when the interactions within and between

295 the particulates are disrupted (Li, Chen, \& Mercadé-Prieto, 2017; Li, Zhao, Chen, \& Mercadé-

296 Prieto, 2016; Mercadé-Prieto et al., 2016). Basic amino acid treatments either did not result in a

297 significant change or decreased the swelling ratio. At $\mathrm{pH} 7.59$, the swelling ratio of the control

298 and histidine-treated WPI gels was considerably higher $(P<0.0 .5)$ than that of the lysine and

299 arginine-treated WPI gels. The swelling ratio of the control and histidine-treated WPI gels

300 decreased at higher $\mathrm{pHs}$, while the swelling ratio of the lysine and arginine-treated gels peaked at 
pH 9.74 and decreased thereafter. Swelling is an equilibrium between water influx-induced gel

302 stretch and retraction of the cross-linked gel network (Gunasekaran, 2008). Lysine and arginine

303 have a strong charge screening effect at $\mathrm{pH} 7.59$ and resulted in a lower negative $\zeta$-potential of

304 the WPI as compared to histidine and the control (Fig.1B). Thus, the lysine and arginine-treated

305 WPI gels had less charged groups and a weaker osmotic pressure to attract water as compared to

306 the control or histidine-treated gels at pH 7.59 (Wang et al., 2019). At higher pHs, the excessive

307 electrostatic repulsions resulted in a poorly interconnected gel matrix as evident by the weak gel

308 strength and springiness (Fig. 3). The declined gel elasticity was likely responsible for the

309 reduction in swelling ratio at $\mathrm{pHs} 9.74-10.76$.

\section{3.5. Protein leachability}

312 Protein leachability of the control WPI gel was the highest at pHs 2.0 and 5.2 and

313 decreased at higher $\mathrm{pHs}$ (Fig. 5). At pH 2.0, the leached-out proteins were predominantly $\beta$ -

314 lactoglobulin (Fig. 6). Under acidic condition, the thiolate to thiol reaction and the thiol/disulfide

315 exchange were inhibited, which hindered the cross-linking of $\beta$-lactoglobulins (Monahan et al.,

316 1995; Zhou et al., 2008). The lysine and arginine treatments significantly reduced protein

317 leachability at $\mathrm{pH} 2.0(P<0.05)$. Lysine and arginine can alter protein structure and expose

318 reactive sulfhydryl groups (Guo et al., 2015; Lei et al., 2016; Lei et al., 2017). Therefore, more

$319 \beta$-lactoglobulin was retained in the gel network through disulfide cross-linking in the presence of

320 lysine and arginine. At higher $\mathrm{pHs}$, the leached-out proteins were mostly polymerized $\alpha$ -

321 lactalbumins and $\beta$-lactoglobulins. These protein polymers were stabilized not only by disulfide

322 bonds but also by covalent bonds of other kinds (e.g., dityrosine bonds, carbonyl-amine bonds)

323 as they cannot be completely dissociated by $\beta$-mercaptoethanol (Cui, Xiong, Kong, Zhao, \& Liu, 
324 2012). High molecular weight protein aggregates unable to enter the separating gels were

325 observed at pHs 7.59 and 9.74 under non-reducing conditions. In the presence of $\beta$ -

326 mercaptoethanol, the protein aggregates disappeared with concomitant appearance of $\beta$ -

327 lactoglobulin indicating the aggregates were formed through disulfide cross-linking of $\beta$ -

328 lactoglobulins. The addition of basic amino acids did not change the protein leachability at pHs

329 5.2-10.76, except for histidine, which resulted in a higher protein leachability at all pHs. It has

330 been reported that histidine and more specifically, the imidazole ring, can suppress protein

331 aggregation by altering the surface charge and structure of the protein (Chen et al., 2016; Gao et

332 al., 2018; Guo et al., 2015), which explains the elevated protein leachability.

\section{3.6. Gel microstructure}

335 The microstructures of the WPI gels are illustrated in Fig. 7. At pH 5.2, WPI formed

336 particulate gels that are composed of coarsely aggregated spherical particles. The lysine-WPI gel

337 exhibited a distinct microstructure at $\mathrm{pH}$ 5.2, in which the particles were partially fused. Lysine

338 has been reported to cause unfolding of globular proteins (Cando et al., 2016; Guo et al., 2015),

339 which may expose more junction zones and promote the formation of stranded structures. The

340 change in microstructure was likely responsible for the improved WHC at pH 5.2 (Fig. 4A). At

341 pHs away from the pI, the WPI formed strand-like gels with relatively smooth surface. The

342 cross-sections of the WPI gels in the presence of basic amino acids displayed a wider distribution

343 of small cavities and less concave-convex surface in comparison to the control, which were

344 indicative of a more porous and uniform structure and explained the improved WHC by basic

345 amino acids (Figure 4A). Similar changes in the gel microstructure as a result of basic amino

346 acids treatments have been reported (Fu et al., 2017; Lei et al., 2016; Lei et al., 2017; Qin et al., 
347 2015; Zhou, Li, \& Tan, 2014; Zhou, Li, Tan, \& Sun, 2014). Basic amino acids can act as cationic

348 surfactants and interact with the oppositely charged protein, provoking the unfolding of the

349 protein and exposure of hydrophobic regions, which facilitates protein aggregation (Fuda,

350 Bhatia, Pyle, \& Jauregi, 2005).

351 4. Conclusion

The results from this study suggested that basic amino acids modified WPI gels in a pH-

353 and amino acid-dependent manner. This was achieved by altering the surface charge and

354 structure of the whey proteins. At $\mathrm{pH} 5.2$ where proteins carry minimum net charge and form a

355 particulate gel, basic amino acids had little influence on the gel functional properties except for

356 lysine, which fused the particulates and resulted in an enhanced water holding capacity. At pHs

357 away from 5.2, basic amino acid treatments resulted in a more uniform and porous gel matrix

358 that can better entrap water. Basic amino acids also facilitated $\beta$-lactoglobulin cross-linking and

359 improved texture profile of the gel. In conclusion, basic amino acids can serve as natural,

360 inexpensive, and non-allergenic additives that can enhance various properties of the WPI gels.

361 Based on the $\mathrm{pH}$ and desired attributes of the product, one can select the appropriate amino acids

362 as the gel enhancer.

363

\section{Conflict of interest}

365 The authors declare no conflict of interest.

\section{Acknowledgment}

368 This research was supported by the National Natural Science Foundation of China (Grant

369 No. 31401530), Oversea Study Fellowship (Jiangsu-UK 20+20 World Class University 
370 Consortium) from Jiangsu Provincial Department of Education/Nanjing Forestry University (to

371 Y.S.), and California State University, Los Angeles Research, Scholarship and Creative

372 Activities Grant Program.

373

374 References

375 Abaee, A., Mohammadian, M., \& Jafari, S. M. (2017). Whey and soy protein-based hydrogels and nano-hydrogels as bioactive delivery systems. Trends in Food Science \& Technology, 70, 69-81.

Bourne, M. (2002). Food texture and viscosity: concept and measurement: Elsevier.

Brodkorb, A., Croguennec, T., Bouhallab, S., \& Kehoe, J. J. (2016). Heat-induced denaturation, aggregation and gelation of whey proteins. In Advanced Dairy Chemistry (pp. 155-178): Springer.

Cando, D., Herranz, B., Borderías, A. J., \& Moreno, H. M. (2016). Different additives to enhance the gelation of surimi gel with reduced sodium content. Food Chemistry, 196, 791-799.

Chen, X., Zou, Y., Han, M., Pan, L., Xing, T., Xu, X., \& Zhou, G. (2016). Solubilisation of myosin in a solution of low ionic strength L-histidine: Significance of the imidazole ring. Food Chemistry, 196, 42-49.

Cheng, Y., Chen, J., \& Xiong, Y. L. (2010). Chromatographic separation and tandem MS identification of active peptides in potato protein hydrolysate that inhibit autoxidation of soybean oil-in-water emulsions. Journal of Agricultural and Food Chemistry, 58(15), $8825-8832$. 
Cheng, Y., Donkor, P. O., Ren, X., Wu, J., Agyemang, K., Ayim, I., \& Ma, H. (2019). Effect of ultrasound pretreatment with mono-frequency and simultaneous dual frequency on the mechanical properties and microstructure of whey protein emulsion gels. Food Hydrocolloids, 89, 434-442.

Cui, X., Xiong, Y. L., Kong, B., Zhao, X., \& Liu, N. (2012). Hydroxyl radical-stressed whey protein isolate: Chemical and structural properties. Food and Bioprocess Technology, 5(6), 2454-2461.

Felicio, T., Esmerino, E., Vidal, V., Cappato, L., Garcia, R., Cavalcanti, R., . . Silva, M. (2016). Physico-chemical changes during storage and sensory acceptance of low sodium probiotic Minas cheese added with arginine. Food Chemistry, 196, 628-637.

Fu, Y., Zheng, Y., Lei, Z., Xu, P., \& Zhou, C. (2017). Gelling properties of myosin as affected by L-lysine and L-arginine by changing the main molecular forces and microstructure. International Journal of Food Properties, 20(sup1), S884-S898.

Fuda, E., Bhatia, D., Pyle, D. L., \& Jauregi, P. (2005). Selective separation of $\beta$-lactoglobulin from sweet whey using CGAs generated from the cationic surfactant CTAB. Biotechnology and Bioengineering, 90(5), 532-542.

Gao, R., Wang, Y., Mu, J., Shi, T., \& Yuan, L. (2018). Effect of L-histidine on the heat-induced aggregation of bighead carp (Aristichthys nobilis) myosin in low/high ionic strength solution. Food Hydrocolloids, 75, 174-181.

Gunasekaran, S. (2008). Whey protein hydrogels and nanoparticles for encapsulation and controlled delivery of bioactive compounds. In C. I. Onwulata \& P. J. Huth (Eds.), Whey Processing, Functionality and Health Benefits (pp. 227-284): John Wiley \& Sons, Inc. 
414 Guo, X., Peng, Z., Zhang, Y., Liu, B., \& Cui, Y. (2015). The solubility and conformational 415 characteristics of porcine myosin as affected by the presence of L-lysine and L-histidine. Food Chemistry, 170, 212-217.

417 Guo, Y., Harris, P., Kaur, A., Pastrana, L., \& Jauregi, P. (2017). Characterisation of $\beta$ lactoglobulin nanoparticles and their binding to caffeine. Food Hydrocolloids, 71, 85-93.

Havea, P., Watkinson, P., \& Kuhn-Sherlock, B. (2009). Heat-induced whey protein gels: Proteinprotein interactions and functional properties. Journal of Agricultural and Food Chemistry, 57(4), 1506-1512.

Hayakawa, T., Yoshida, Y., Yasui, M., Ito, T., Iwasaki, T., Wakamatsu, J., Hattori, A.,

Ikeda, S., \& Foegeding, E. (1999). Effects of lecithin on thermally induced whey protein isolate Nishimura, T. (2012). Heat-induced gelation of myosin in a low ionic strength solution gels. Food Hydrocolloids, 13(3), 239-244.

Ikeda, S., Foegeding, E. A., \& Hagiwara, T. (1999). Rheological study on the fractal nature of the protein gel structure. Langmuir, 15(25), 8584-8589.

Ikeda, S., \& Morris, V. J. (2002). Fine-stranded and particulate aggregates of heat-denatured whey proteins visualized by atomic force microscopy. Biomacromolecules, 3(2), 382389.

Laemmli, U. K. (1970). Cleavage of structural proteins during the assembly of the head of bacteriophage T4. Nature, 227(5259), 680-685.

Langton, M., \& Hermansson, A.-M. (1992). Fine-stranded and particulate gels of $\beta$-lactoglobulin and whey protein at varying pH. Food Hydrocolloids, 5(6), 523-539. 
Lei, Z., Fu, Y., Xu, P., Zheng, Y., \& Zhou, C. (2016). Effects of L-arginine on the physicochemical and gel properties of chicken actomyosin. International Journal of Biological Macromolecules, 92, 1258-1265.

Lei, Z., Fu, Y., Zheng, Y., Xu, P., \& Zhou, C. (2017). Effects of L-lysine on thermal gelation properties of chicken breast actomyosin. Food Science and Biotechnology, 26(3), 549556.

Li, H., Chen, X. D., \& Mercadé-Prieto, R. (2017). Elastic modulus and equilibrium swelling of stranded and particulate protein hydrogels at acid pH. Food Hydrocolloids, 71, 168-175.

Li, H., Zhao, L., Chen, X. D., \& Mercadé-Prieto, R. (2016). Swelling of whey and egg white protein hydrogels with stranded and particulate microstructures. International Journal of Biological Macromolecules, 83, 152-159.

Li, S., Li, L., Zhu, X., Ning, C., Cai, K., \& Zhou, C. (2019). Conformational and charge changes induced by L-arginine and L-lysine increase the solubility of chicken myosin. Food Hydrocolloids, 89, 330-336.

Li, S., Zheng, Y., Xu, P., Zhu, X., \& Zhou, C. (2018). L-lysine and L-arginine inhibit myosin aggregation and interact with acidic amino acid residues of myosin: The role in increasing myosin solubility. Food Chemistry, 242, 22-28.

Liu, M., Wang, Y., Jiang, L., Xia, Q., Qiu, Y., Fan, L., Zhou, J., Zhao, L. (2015). Effect of $\gamma$ aminobutyric acid on the physicochemical, rheological and sensory properties of yoghurt. International Journal of Dairy Technology, 68(4), 503-510.

Mercadé-Prieto, R., Zhao, H., Zhang, M., Li, H., Zhao, L., \& Chen, X. D. (2016). Dissolution and swelling of soy protein isolate hydrogels in alkali. Food Hydrocolloids, 56, 285-291. 
Miyatake, T., Yoshizawa, S., Arakawa, T., \& Shiraki, K. (2016). Charge state of arginine as an additive on heat-induced protein aggregation. International Journal of Biological Macromolecules, 87, 563-569.

Monahan, F. J., German, J. B., \& Kinsella, J. E. (1995). Effect of pH and temperature on protein unfolding and thiol/disulfide interchange reactions during heat-induced gelation of whey proteins. Journal of Agricultural and Food Chemistry, 43(1), 46-52.

Ozel, B., Cikrikci, S., Aydin, O., \& Oztop, M. H. (2017). Polysaccharide blended whey protein isolate-(WPI) hydrogels: A physicochemical and controlled release study. Food Hydrocolloids, 71, 35-46.

Primacella, M., Fei, T., Acevedo, N., \& Wang, T. (2018). Effect of food additives on egg yolk gelation induced by freezing. Food Chemistry, 263, 142-150.

Qin, H., Xu, P., Zhou, C., \& Wang, Y. (2015). Effects of L-arginine on water holding capacity and texture of heat-induced gel of salt-soluble proteins from breast muscle. LWT-Food Science and Technology, 63(2), 912-918.

Stading, M., \& Hermansson, A.-M. (1991). Large deformation properties of $\beta$-lactoglobulin gel structures. Food Hydrocolloids, 5(4), 339-352.

Stading, M., Langton, M., \& Hermansson, A.-M. (1993). Microstructure and rheological behaviour of particulate $\beta$-lactoglobulin gels. Food Hydrocolloids, 7(3), 195-212.

Unterhaslberger, G., Schmitt, C., Sanchez, C., Appolonia-Nouzille, C., \& Raemy, A. (2006). Heat denaturation and aggregation of $\beta$-lactoglobulin enriched WPI in the presence of arginine $\mathrm{HCl}, \mathrm{NaCl}$ and guanidinium $\mathrm{HCl}$ at $\mathrm{pH} 4.0$ and 7.0. Food Hydrocolloids, 20(7), 1006-1019. 
Wang, Y., Xiong, Y. L., Rentfrow, G. K., \& Newman, M. C. (2013). Oxidation promotes crosslinking but impairs film-forming properties of whey proteins. Journal of Food Engineering, 115(1), 11-19.

Wang, Y., Zhao, J., Liu, C., \& Li, W. (2019). Influence of $\gamma$-aminobutyric acid on gelling properties of heat-induced whey protein gels. Food Hydrocolloids, 94, 287-293.

Weel, K. G., Boelrijk, A. E., Alting, A. C., van Mil, P. J., Burger, J. J., Gruppen, H., Voragen, A. G. J., \& Smit, G. (2002). Flavor release and perception of flavored whey protein gels: Perception is determined by texture rather than by release. Journal of Agricultural and Food Chemistry, 50(18), 5149-5155.

Wu, M., Xiong, Y. L., Chen, J., Tang, X., \& Zhou, G. (2009). Rheological and microstructural properties of porcine myofibrillar protein-lipid emulsion composite gels. Journal of Food Science, 74(4), E207-E217.

Xu, P., Zheng, Y., Zhu, X., Li, S., \& Zhou, C. (2018). L-lysine and L-arginine inhibit the oxidation of lipids and proteins of emulsion sausage by chelating iron ion and scavenging radical. Asian-Australasian Journal of Animal Sciences, 31(6), 905-913.

Zhang, Y., Wu, J., Jamali, M. A., Guo, X., \& Peng, Z. (2017). Heat-induced gel properties of porcine myosin in a sodium chloride solution containing L-lysine and L-histidine. $L W T$ Food Science and Technology, 85, 16-21.

Wang, Y., Liu, C., Ma, T., \& Zhao, J. (2019). Physicochemical and functional properties of $\gamma$ aminobutyric acid-treated soy proteins. Food Chemistry, 295, 267-273.

Zhou, C., Li, J., \& Tan, S. (2014). Effect of L-lysine on the physicochemical properties of pork sausage. Food Science and Biotechnology, 23(3), 775-780. 
502

503

504

505

506

507

508

509

510

511

Zhou, C., Li, J., Tan, S., \& Sun, G. (2014). Effects of L-arginine on physicochemical and sensory characteristics of pork sausage. Advance Journal of Food Science and Technology, 6(5), $660-667$.

Zhou, C., Ye, H., Nishiumi, T., Qin, H., \& Chen, C. (2014). L-histidine enhances stability of hemoglobin concentrates by coordinating with free iron. Food Research International, $62,637-643$.

Zhou, C., Ye, H., Wang, H., Qin, H., \& Li, J. (2015). Coordination of L-arginine and iron cation improves stability of hemoglobin concentrates. European Food Research and Technology, 240(4), 743-751.

Zhou, P., Liu, X., \& Labuza, T. P. (2008). Moisture-induced aggregation of whey proteins in a protein/buffer model system. Journal of Agricultural and Food Chemistry, 56(6), 20482054.

Zhu, X., Li, L., Li, S., Ning, C., \& Zhou, C. (2019). L-arginine/L-lysine improves emulsion stability of chicken sausage by increasing electrostatic repulsion of emulsion droplet and decreasing the interfacial tension of soybean oil-water. Food Hydrocolloids, 89, 492-502.

Zhu, X., Ning, C., Li, S., Xu, P., Zheng, Y., \& Zhou, C. (2018). Effects of L-lysine/L-arginine on the emulsion stability, textural, rheological and microstructural characteristics of chicken sausages. International Journal of Food Science \& Technology, 53(1), 88-96. 
521 Color of whey protein isolate gels at different $\mathrm{pHs}$ with and without $0.5 \%(\mathrm{w} / \mathrm{v})$ histidine (His),

522 lysine (Lys), and arginine (Arg).

\begin{tabular}{|c|c|c|c|c|}
\hline \multirow[t]{2}{*}{ Gel sample } & \multirow[t]{2}{*}{$\mathrm{pH}$} & \multicolumn{3}{|c|}{ Color } \\
\hline & & $\mathrm{L}^{*}$ & $\mathrm{a}^{*}$ & $\mathrm{~b}^{*}$ \\
\hline \multirow[t]{5}{*}{ Control } & 2.0 & $38.43 \pm 0.51^{\mathrm{ghi}}$ & $-1.87 \pm 0.06^{c}$ & $-2.04 \pm 0.05^{\mathrm{gh}}$ \\
\hline & 5.2 & $90.61 \pm 0.57^{b}$ & $-2.07 \pm 0.07^{\text {cde }}$ & $5.17 \pm 0.38^{\mathrm{c}}$ \\
\hline & 7.59 & $41.47 \pm 1.15^{\mathrm{def}}$ & $-2.53 \pm 0.08^{\mathrm{ghi}}$ & $-3.01 \pm 0.05^{\mathrm{jk}}$ \\
\hline & 9.74 & $33.88 \pm 0.78^{\mathrm{k}}$ & $-2.11 \pm 0.09^{\text {cde }}$ & $-2.28 \pm 0.11^{\mathrm{hi}}$ \\
\hline & 10.76 & $37.39 \pm 1.62^{\mathrm{ij}}$ & $-3.64 \pm 0.28^{\operatorname{lm}}$ & $3.71 \pm 0.41^{\mathrm{d}}$ \\
\hline \multirow[t]{5}{*}{$0.5 \%$ His } & 2.0 & $43.35 \pm 0.74^{\mathrm{cde}}$ & $-2.30 \pm 0.10^{\mathrm{efg}}$ & $-2.91 \pm 0.14^{\mathrm{jk}}$ \\
\hline & 5.2 & $92.40 \pm 0.20^{\mathrm{ab}}$ & $-1.50 \pm 0.02^{b}$ & $6.62 \pm 0.04^{\mathrm{a}}$ \\
\hline & 7.59 & $43.64 \pm 1.70^{\mathrm{cd}}$ & $-2.86 \pm 0.19^{j k}$ & $-4.14 \pm 0.19^{1}$ \\
\hline & 9.74 & $36.53 \pm 0.58^{\mathrm{ij}}$ & $-2.66 \pm 0.07^{\mathrm{hij}}$ & $-1.61 \pm 0.06^{\mathrm{g}}$ \\
\hline & 10.76 & $41.18 \pm 1.63^{\mathrm{def}}$ & $-3.69 \pm 0.22^{\mathrm{lm}}$ & $3.01 \pm 0.80^{\mathrm{e}}$ \\
\hline \multirow[t]{5}{*}{$0.5 \%$ Lys } & 2.0 & $42.14 \pm 0.75^{\mathrm{def}}$ & $-2.18 \pm 0.05^{\mathrm{def}}$ & $-1.81 \pm 0.02^{\mathrm{gh}}$ \\
\hline & 5.2 & $90.86 \pm 0.11^{\mathrm{b}}$ & $-2.05 \pm 0.01^{\text {cde }}$ & $6.00 \pm 0.11^{b}$ \\
\hline & 7.59 & $40.87 \pm 1.39^{\mathrm{efg}}$ & $-2.75 \pm 0.10^{\mathrm{ijk}}$ & $-4.47 \pm 0.05^{1}$ \\
\hline & 9.74 & $44.73 \pm 1.22^{\mathrm{c}}$ & $-3.48 \pm 0.10^{1}$ & $-0.62 \pm 0.26^{f}$ \\
\hline & 10.76 & $40.03 \pm 2.00^{\mathrm{fgh}}$ & $-4.16 \pm 0.33^{n}$ & $6.15 \pm 0.70^{\mathrm{ab}}$ \\
\hline \multirow[t]{5}{*}{$0.5 \%$ Arg } & 2.0 & $42.27 \pm 2.46^{\text {cdef }}$ & $-2.00 \pm 0.09^{\mathrm{cd}}$ & $-2.61 \pm 0.15^{\mathrm{ij}}$ \\
\hline & 5.2 & $94.50 \pm 0.56^{\mathrm{a}}$ & $-0.99 \pm 0.01^{\mathrm{a}}$ & $6.41 \pm 0.10^{\mathrm{ab}}$ \\
\hline & 7.59 & $40.99 \pm 0.55^{\mathrm{ef}}$ & $-2.42 \pm 0.04^{\mathrm{fgh}}$ & $-3.39 \pm 0.05^{\mathrm{k}}$ \\
\hline & 9.74 & $35.34 \pm 3.98^{\mathrm{jk}}$ & $-2.99 \pm 0.23^{\mathrm{k}}$ & $-1.56 \pm 0.41^{\mathrm{g}}$ \\
\hline & 10.76 & $37.80 \pm 1.99^{h i j}$ & $-3.88 \pm 0.41^{\mathrm{m}}$ & $5.94 \pm 0.52^{b}$ \\
\hline
\end{tabular}

523 Values share no common letters differ significantly $(P<0.05)$. 

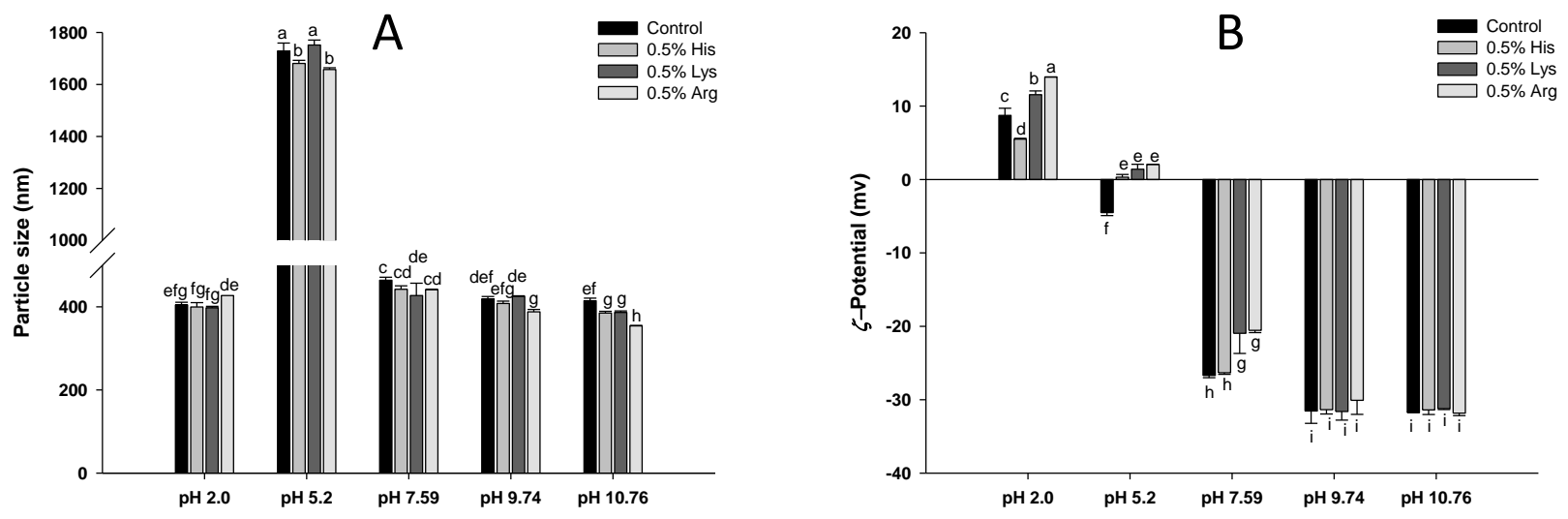

526 Fig 1. Particle size (A) and $\zeta$-potential (B) of whey protein isolate sols at different $\mathrm{pHs}$ in the

527 absence and presence of $0.5 \%$ (w/v) histidine (His), lysine (Lys), or arginine (Arg). Values share

528 no common letters differ significantly $(P<0.05)$. 


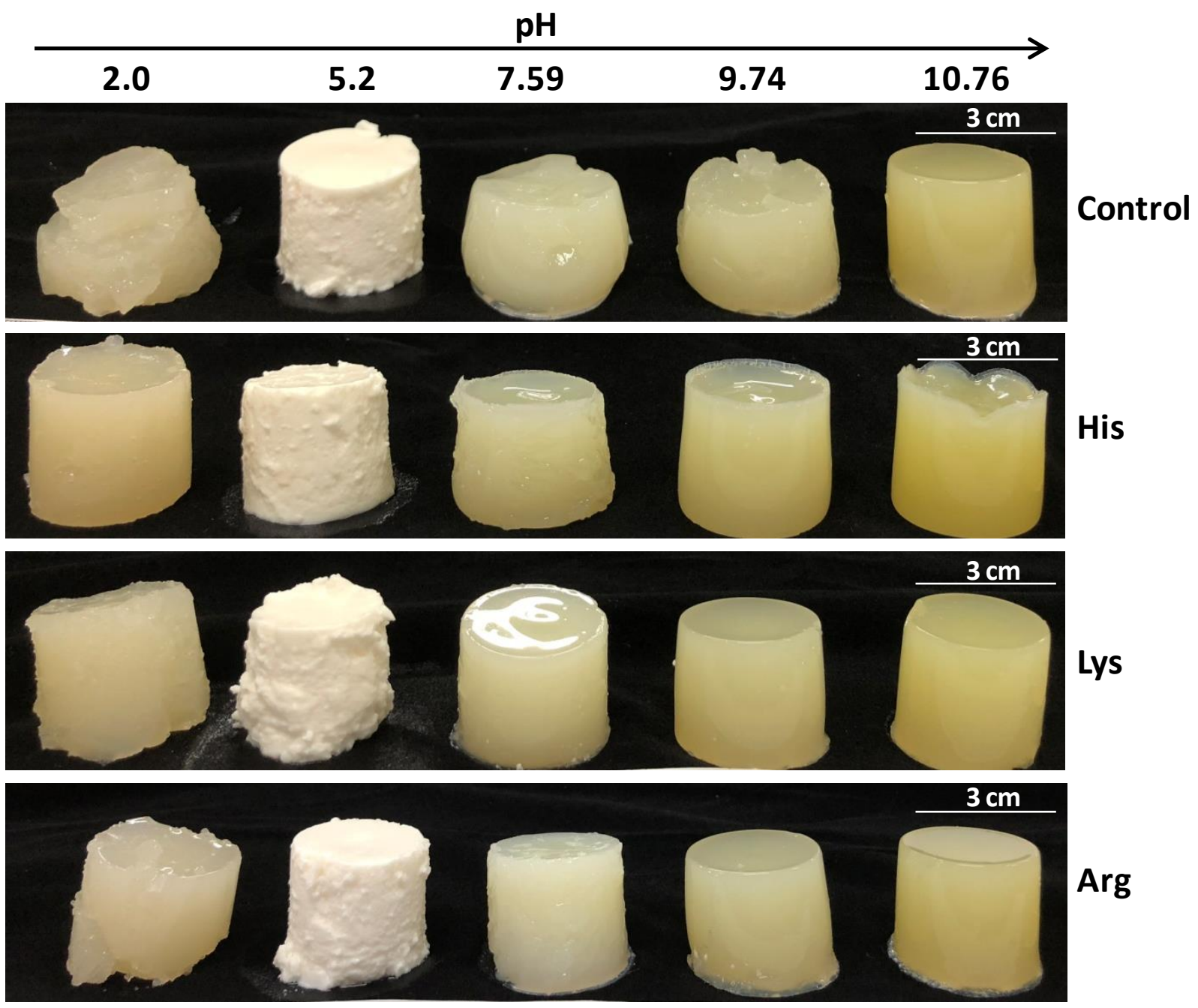

531 Fig. 2. Appearance of whey protein isolate gels at different pHs in the absence and presence of

$5320.5 \%(w / v)$ histidine (His), lysine (Lys), or arginine (Arg). 

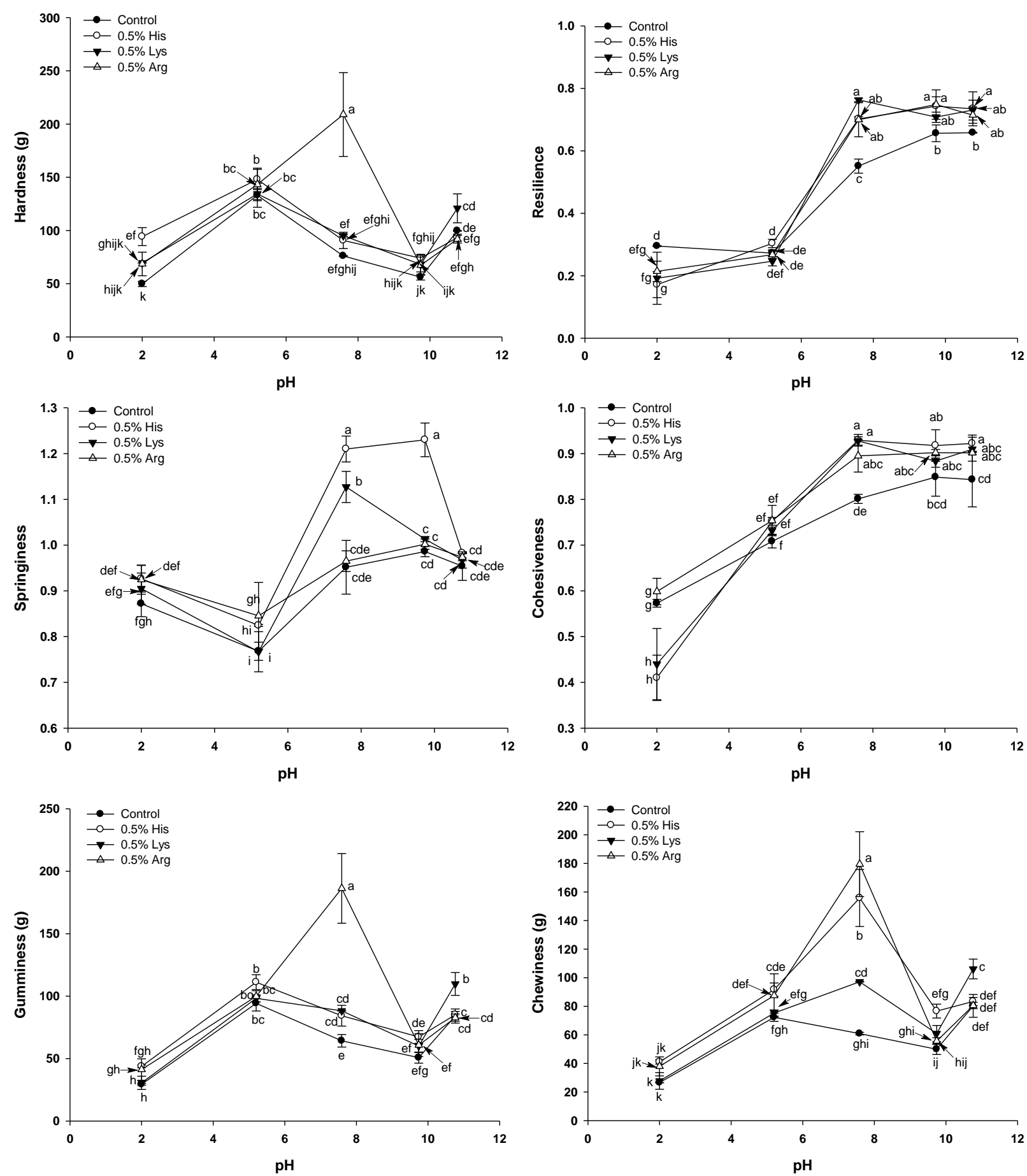

535 Fig. 3. Texture profile analysis of whey protein isolate gels at different $\mathrm{pHs}$ in the absence and

536 presence of $0.5 \%$ (w/v) histidine (His), lysine (Lys), or arginine (Arg). Values share no common

537 letters differ significantly $(P<0.05)$. 

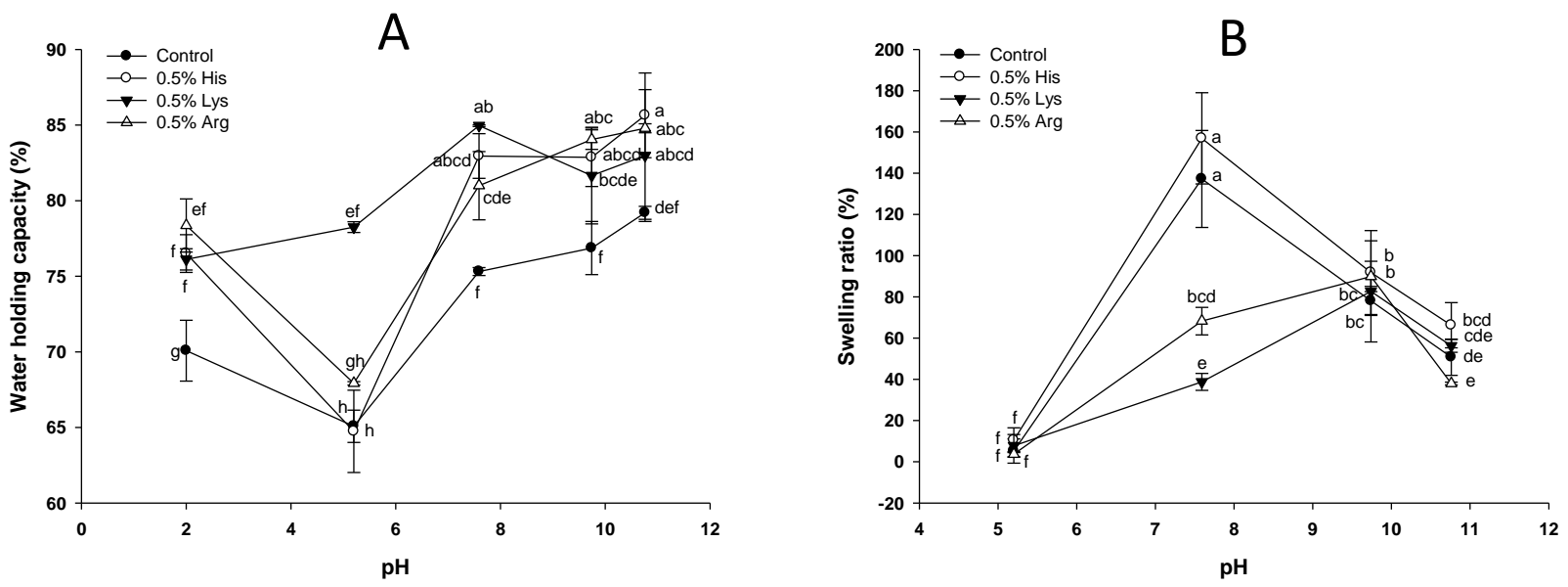

540 Fig. 4. Water holding capacity (A) and swelling ratio (B) of whey protein isolate gels at different

$541 \mathrm{pHs}$ in the absence and presence of $0.5 \%(\mathrm{w} / \mathrm{v})$ histidine (His), lysine (Lys), or arginine (Arg).

542 Values share no common letters differ significantly $(P<0.05)$. 


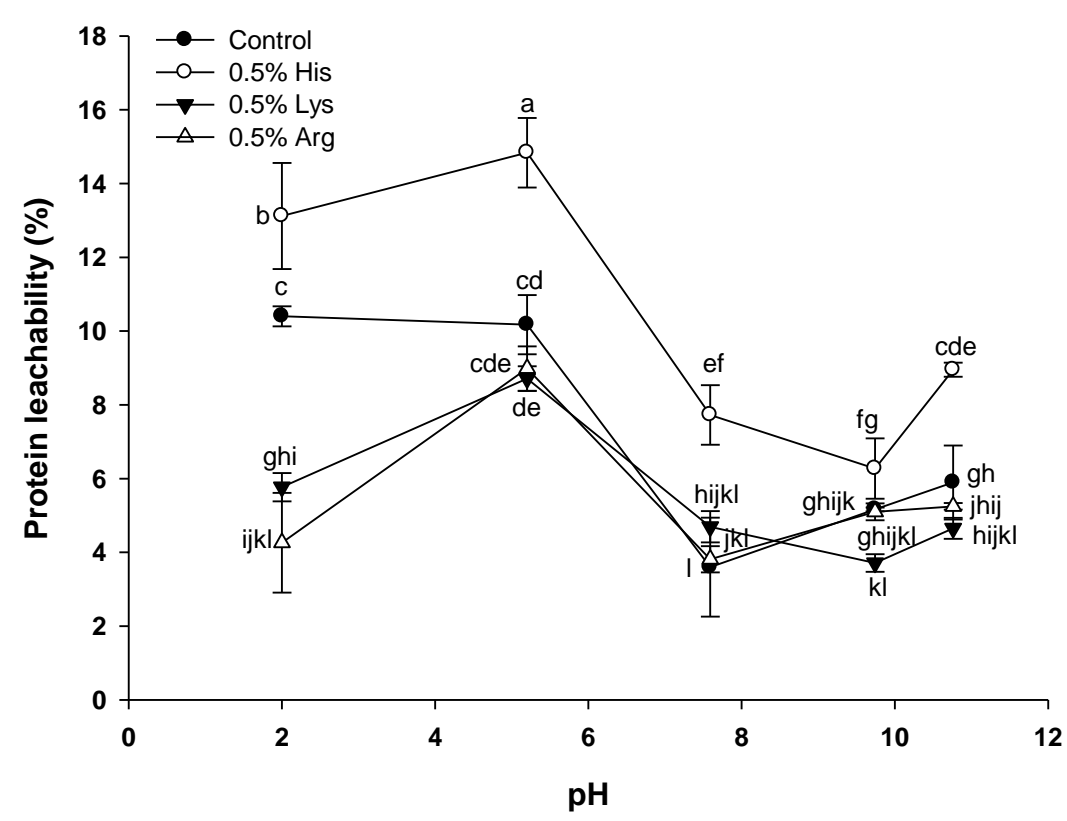

545 Fig. 5. Protein leachability of whey protein isolate gels at different pHs in the absence and

546 presence of $0.5 \%(\mathrm{w} / \mathrm{v})$ histidine (His), lysine (Lys), or arginine (Arg). Values share no common

547 letters differ significantly $(P<0.05)$. 


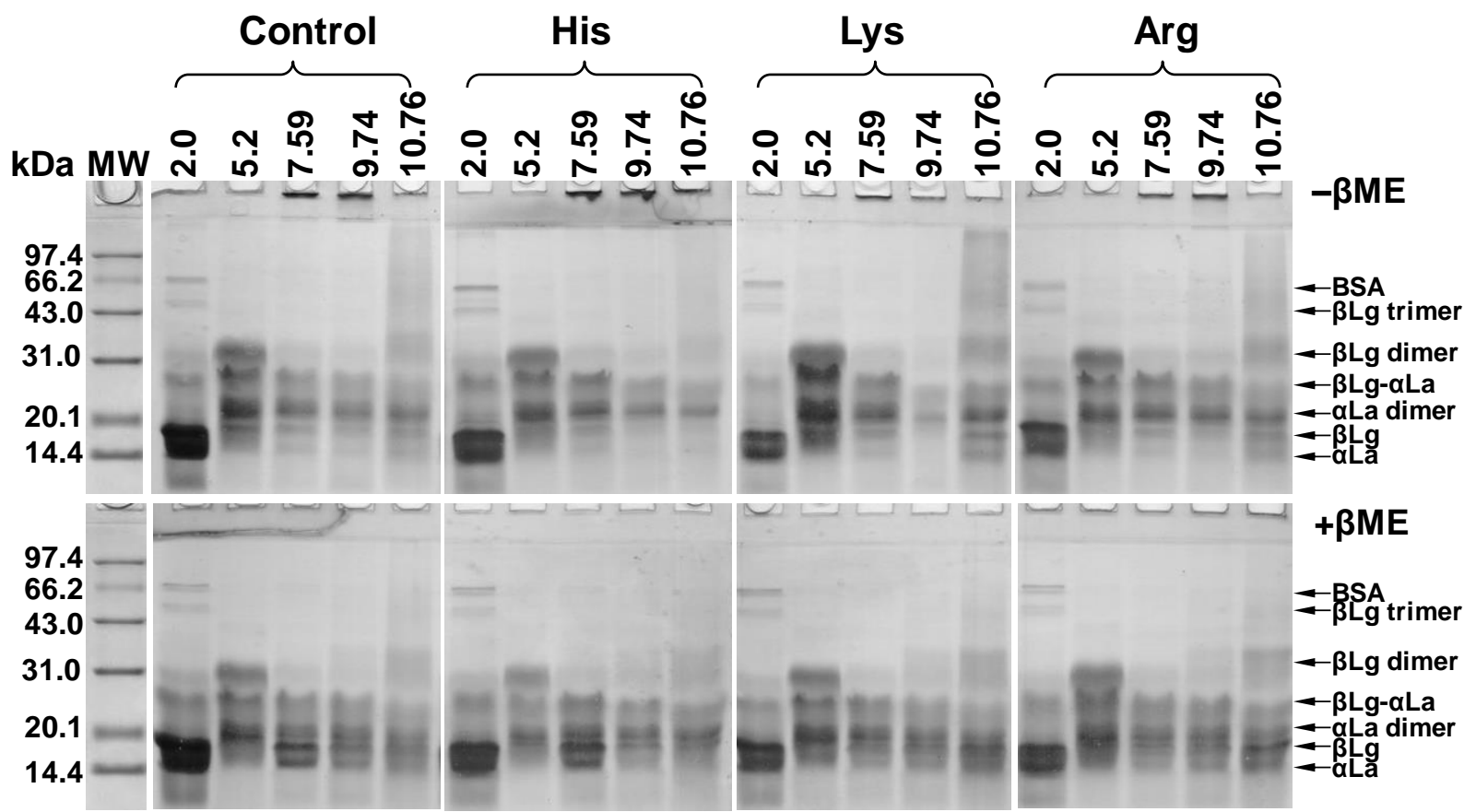

550 Fig. 6. Sodium dodecyl sulfate-polyacrylamide gel electrophoresis (SDS-PAGE) of proteins

551 leached out of whey protein isolate gels at different $\mathrm{pHs}$ in the absence and presence of $0.5 \%$

552 (w/v) histidine (His), lysine (Lys), or arginine (Arg). The gels were run under reducing (+ßME)

553 and non-reducing (- $\beta \mathrm{ME})$ conditions. MW: molecular weight; BSA: bovine serum albumin; $\beta \mathrm{Lg}$ :

$554 \beta$-lactoglobulin; $\alpha$ La: $\alpha$-lactalbumin; $\beta$ ME: $\beta$-mercaptoethanol. 


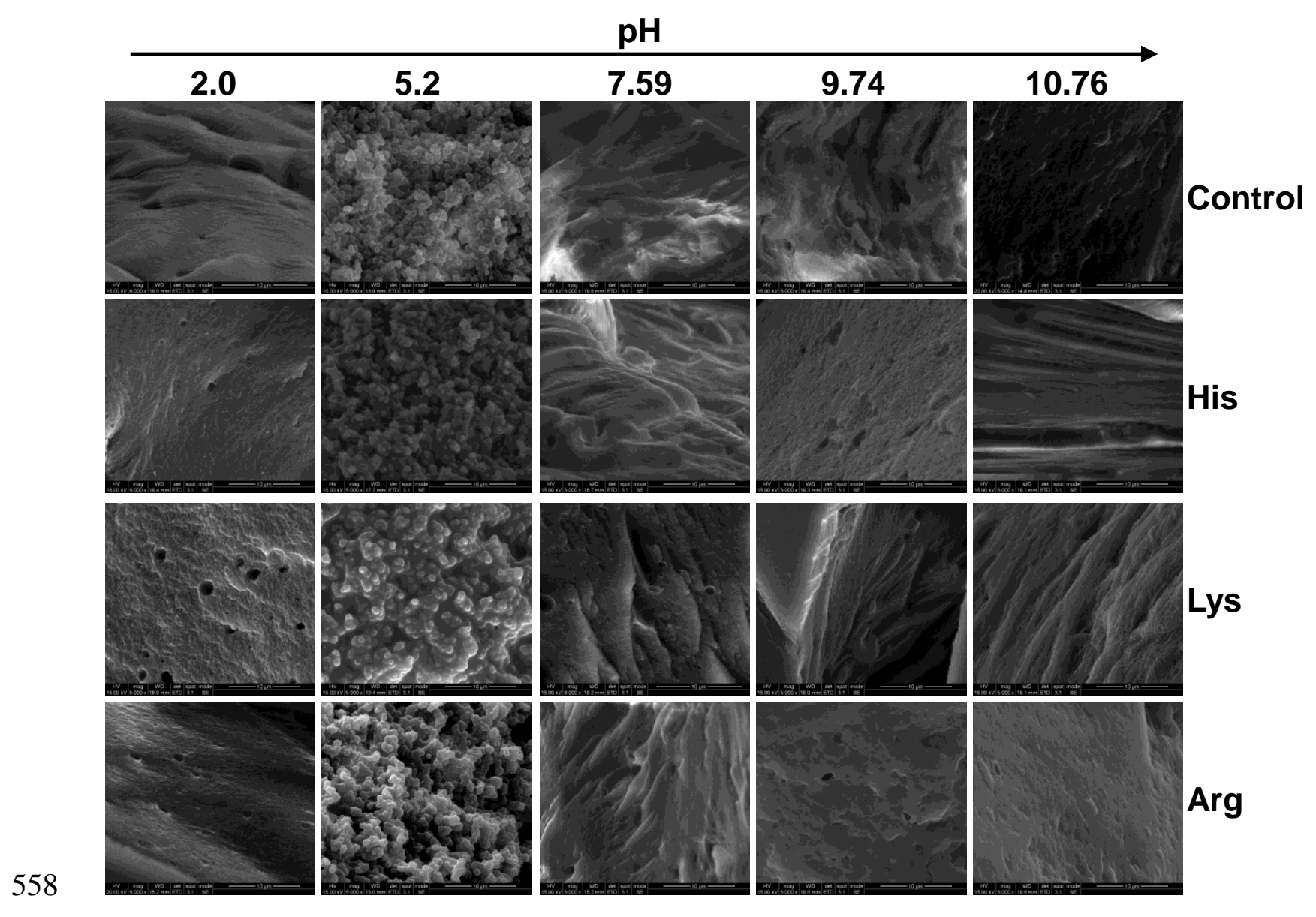

559 Fig. 7. Scanning electron microscopy image of the cross-section of whey protein isolate gels at

560 different $\mathrm{pHs}$ in the absence and presence of $0.5 \%(\mathrm{w} / \mathrm{v})$ histidine (His), lysine (Lys), or arginine 561 (Arg). 